\title{
Urban identity, perception, and urban design
}

\author{
Mahyar Arefi ${ }^{1}$. Patricia Aelbrecht ${ }^{2}$
}

Accepted: 29 January 2022 / Published online: 9 February 2022

(c) The Author(s), under exclusive licence to Springer Nature Limited 2022, corrected publication 2022

That urban perception and identity play pivotal roles in urban design is no more than a truism for both academics and practitioners. However, a wide range of direct or indirect factors surrounding urban perception and identity have expanded and diversified these multifarious, interdisciplinary discourses. The six articles published in this issue of Urban Design International highlight these debates.

The first article on high-density mobile LiDAR (Light Detection and Ranging) by Golombek and Marshall examines the streetscape features and attributes. Cities with better streetscapes tend to attract more people in everyday life interactions. While the attributes associated with streetscapes remain somewhat debatable, and in some cases, conflicted, new measurement methods have opened new horizons for revisiting their purposes and functionalities. This research examines mobile LiDAR as a viable method of measuring the streetscape. Using highly accurate measurement methods, this study maps several walkable town center segments in Colorado with high tech assessment methods. Proving useful in measuring streetscape attributes, mobile LiDAR analytics complement time-consuming, and somewhat "subjective, audit-based streetscape measurements" (i.e., enclosure, complexity, transparency, and imageability). The LiDAR method can increase accuracy in measuring variables that to urban designers have, for long, represent subjective concepts.

In the second article on public perception of urban identity by Anastasiou et al., another approach to measuring public perception of urban identity, brings forth a combination of spatial and non-spatial attributes. The former purports more familiar and tangible attributes while the latter conjures up less tangible cultural/historical to social, and even cognitive/emotional attributes including how people use outdoor spaces in their spare time. This research associates

\footnotetext{
Mahyar Arefi

mahyararefi@gmail.com

Jundi-Shapur University of Technology, Dezful, Iran

2 Cardiff University, Cardiff, United Kingdom
}

urban identity measurements with not only spatial characteristics such as "cleanliness, adequate public transportation and functionality of street network," and perceived safety, but also with socio-demographic attributes (i.e., age, gender, family status, and educational attainments), locality dimensions (i.e., bring close or far from the city center), and leisure.

Dwelling on how urban designers come to terms with subjective dimensions of urban perception, brings to mind spontaneity as yet another relevant concept. In other words, one can ask: how does spontaneity affect (urban) perception? Cozzolino addresses the question pertaining to the spontaneous beauty of cities in his article. More to the point, while spontaneous beauty does not occur by design, it certainly complements "beauty as design" or "designed beauty." To draw out this distinction, the author juxtaposes informal settlements and New Towns as manifestations of such complementarities. This way of thinking, according to Cozzolino, provides a dynamic venue for creating "spatial democratization," where people have some degree of freedom to leave their marks on the space. Creative placemaking, especially, tactically-operated, is a case in point.

Beauty and identity too add a certain degree of subjectivity to urban perception. Even though subjectivity, per se, does not convolute these concepts, the scales with which they are measured, cause some confusion. As a familiar concept in urban design research and practice, density is a case in point. Pafka's article on multi-scalar urban densities provides an important analysis in demystifying potential confusions in this sense. The article particularly focuses on two different scales associated with density including MWD (Metropolitan Walkable Density) and UED (Urban Experiential Density), where the former views walkability across a patchwork of neighborhood across the metropolitan level and the latter maps the perceived densities. Putting flesh on the bones of these two concepts shows that New York has one of the highest MWDs. However, the UED analysis reveals "contrasting patterns" in cities like Melbourne and Sydney. But New York and Los Angeles residential densities seem "more even due to density zoning regulations." 
Pakoz et al.'s contribution focuses on yet another aspect of changing urban perceptions in the juxtaposition of public and pseudo-public spaces. The outbreak of COVID-19 and its lingering consequences have particularly affected the public perceptions toward public space usage. Administering over 300 surveys, the authors report a significant decrease in the conventional uses of public space and an increase in the use of virtual public space. This research concludes with a shift from designing large- to small-scale public spaces as its urban design implications while the outbreak lasts.

Finally, Yildiz et al., explore the degrees of publicness in urban design in a university campus in Utrecht, Netherlands. Using Space Syntax, the authors revisit publicness as an important theme with design implications and operationalized in terms of its three components: interaction, display and discovery. A comparative analysis of two public spaces in Utrecht University, they report the differences between the two spaces in terms of their attractiveness or unattractive elements for students.

Mahyar Arefi and Patricia Aelbrecht

Co-Editors,

Urban Design International

Publisher's Note Springer Nature remains neutral with regard to jurisdictional claims in published maps and institutional affiliations. 